\title{
2021 - State of our JCMR
}

\author{
Warren J. Manning ${ }^{1,2^{*}}$ (D)
}

\begin{abstract}
There were 89 articles published in the Journal of Cardiovascular Magnetic Resonance (JCMR) in 2020, including 71 original research papers, 5 technical notes, 6 reviews, 4 Society for Cardiovascular Magnetic Resonance (SCMR) position papers/guidelines/protocols and 3 corrections. The volume was up 12.7\% from 2019 ( $n=79)$ with a corresponding $17.9 \%$ increase in manuscript submissions from 369 to 435 . This led to a slight increase in the acceptance rate from 22 to $23 \%$. The quality of the submissions continues to be high. The $2020 \mathrm{JCMR}$ Impact Factor (which is published in June 2020) slightly increased from 5.361 to 5.364 placing us in the top quartile of Society and cardiac imaging journals. Our 5 year impact factor increased from 5.18 to 6.52. Fourteen years ago, the JCMR was at the forefront of medical and medical society journal migration to the Open-Access format. The Open-Access system has dramatically increased the availability and citation of JCMR publications with accesses now exceeding $1.2 \mathrm{M}$ ! It takes a village to run a journal. JCMR is blessed to have a group of very dedicated Associate Editors, Guest Editors, Journal Club Editors, and Reviewers. I thank each of them for their efforts to ensure that the review process occurs in a timely and responsible manner. These efforts have allowed the JCMR to continue as the premier journal of our field. My role, and the entire process would not be possible without the dedication and efforts of our new managing editor, Jennifer Rodriguez, whose premier organizational efforts have allowed for streamlining of the review process and marked improvement in our time-to-decision (see later). As I begin my 6th and final year as your editor-in-chief, I thank you for entrusting me with the JCMR editorship. I hope that you will continue to send us your very best, high quality manuscripts for JCMR consideration and that our readers will continue to look to JCMR for the very best/state-of-the-art CMR publications. The editorial process continues to be a tremendously fulfilling experience and the opportunity to review manuscripts that reflect the best in our field remains a great joy and true highlight of my week!
\end{abstract}

\section{Background}

In accordance with Open-Access publishing guidelines of our publisher, BMC, the Journal of Cardiovascular Magnetic Resonance (JCMR) articles are published on-line in a continuous fashion and in chronologic number order, with no collating of the articles into sections or special thematic issues. In addition, due to the variability in the author galley review process, articles are sometimes not listed in chronologic order on the JCMR web site. As a result, our second editor-in-chief, Dr. Dudley Pennell

\footnotetext{
*Correspondence: wmanning@bidmc.harvard.edu

${ }^{1}$ Departments of Medicine (Cardiovascular Division) and Radiology,

Beth Israel Deaconess Medical Center, Harvard Medical School, Boston Massachusetts 02215, USA

Full list of author information is available at the end of the article
}

initiated an annual review of all JCMR publications into broad areas of interest or themes, allowing readers to view areas of interest in a single article in relation to each other and contemporaneous JCMR publications. Though I believe this review would be a valuable asset for our readership, I have chosen not to continue this tradition so as to decrease our self-citation rate and potential "delisting" from the annual Impact Factor calculation. Instead, similar to last year, I will focus on conveying information regarding the editorial process as a "State of our JCMR" summary.

The JCMR is the official publication of the Society for Cardiovascular Magnetic Resonance (SCMR). The JCMR published 89 articles in 2020, including 71 original research papers, 5 technical notes, 6 reviews, 4 SCMR position papers/guidelines/protocols and 3 corrections. original author(s) and the source, provide a link to the Creative Commons licence, and indicate if changes were made. The images or other third party material in this article are included in the article's Creative Commons licence, unless indicated otherwise in a credit line to the material. If material is not included in the article's Creative Commons licence and your intended use is not permitted by statutory regulation or exceeds the permitted use, you will need to obtain permission directly from the copyright holder. To view a copy of this licence, visit http://creativecommons.org/licenses/by/4.0/. The Creative Commons Public Domain Dedication waiver (http://creativeco mmons.org/publicdomain/zero/1.0/) applies to the data made available in this article, unless otherwise stated in a credit line to the data. 
The 2020 publication volume was up $12.7 \%$ from 2019 $(\mathrm{n}=79)$ with a corresponding $17.9 \%$ increase in manuscript submissions from 369 to 435 . This led to a slight increase in the acceptance rate from 22 to $23 \%$ (the slight mathematical difference in acceptance/submissions is related to submission year and publication year).

In July 2018, the article processing charge (APC) structure changed with manuscripts for which an SCMR member is the first, co-first, senior or corresponding author receive an $80 \%$ discount to the full $\$ 2500$ APC. Reduced APC fees are also available to those from BMC membership institutions, submitting authors from lower income countries, and for those who request a waiver due to financial hardship. APCs are waived for invited reviews and for Society publications. The APC will not be changing for 2022.

For 2020, the United States $(\mathrm{n}=97)$ and China $(\mathrm{n}=96)$ were the source of nearly $50 \%$ of all JCMR publications followed by Germany $(\mathrm{n}=48)$ and the United Kingdom $(\mathrm{n}=37)$ (Fig. 1). The top three countries for publications were the United States $(n=26)$, Germany $(n=16)$ and the United Kingdom ( $\mathrm{n}=13)$ (Fig. 1).

\section{Impact factor}

Though only one of many journal metrics and not a consideration in our review process, the Clarivate Impact Factor is nonetheless a well-known metric with which many readers are familiar and is a metric often considered by both authors and readers. I am pleased to report that the $2020 J C M R$ Impact Factor (which was released in June 2021 and is based on manuscripts published in 2018 and 2019 that were cited in 2020), slightly increased from 5.361 to 5.364. This impact factor means that the JCMR papers that were published in 2018 and 2019 were cited on average approximately 5.4 times in 2020 . This puts $J C M R$ well positioned in the top tertile (37/142) of journals in the broad categories of "Cardiac and Cardiovascular Systems" and the top quintile (20/133) of "Radiology, Nuclear Medicine and Medical Imaging." In addition, our Journal Citation Indication is 1.44, meaning JCMR has $44 \%$ greater citation impact than the average in its category! The 2021 JCMR impact factor will be released in June 2022, and I will keep you abreast of the results (follow us on Twitter!).

Perhaps more important than the Impact Factor is the frequency that JCMR articles are accessed. Our openaccess format allows for much greater visibility for our authors with the 2020 JCMR annual digital access now exceeding 1,200,000!! - a threshold not achievable with a subscription/print publication of a Society journal. Open-access has "leveled the playing field" so that an electronic search allows JCMR manuscripts to rise to awareness and to then be downloaded without cost. This is a great benefit to our readers, to the greater scientific community, and to our authors.

\section{JCMR editor-in-chief leadership}

Dr. Gerald Pohost (Fig. 2) from the University of Alabama at Birmingham and University of Southern California, Los Angeles, California, USA was the JCMR inaugural

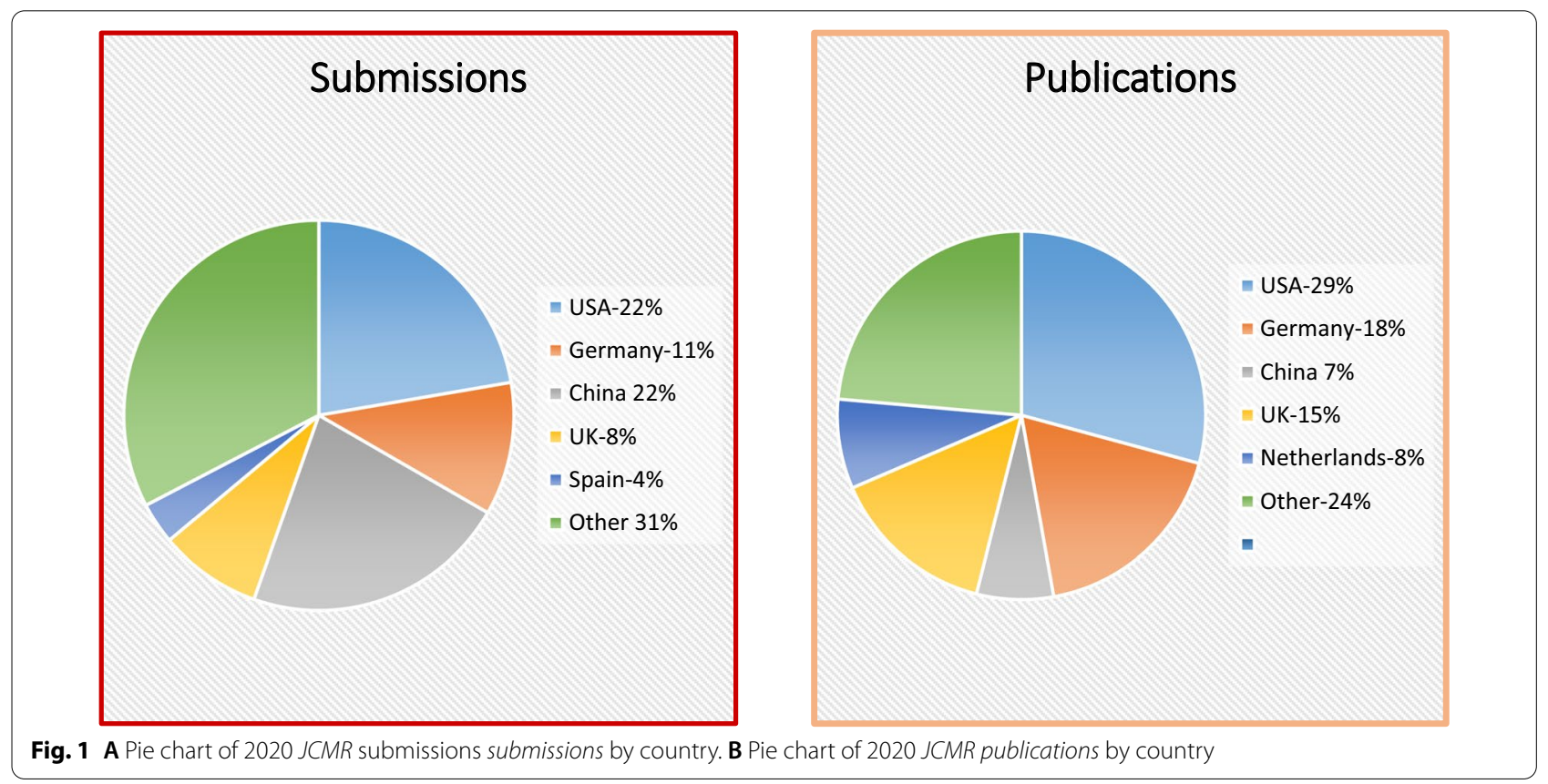


$14^{\text {th }}$ JCMR Gerald M. Pohost Award

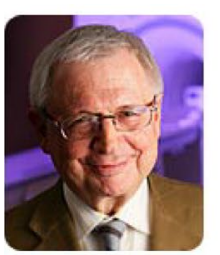

Dr. Pohost

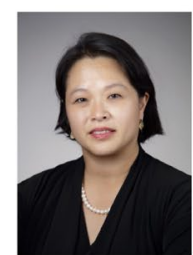

Dr. Bandettini

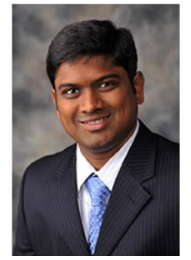

Dr. Reddy

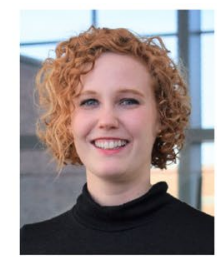

Dr. Campbell-Washburn

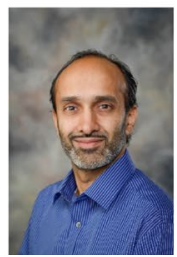

Dr. Hussain

$3^{\text {rd } J C M R}$ Dudley Pennell Award

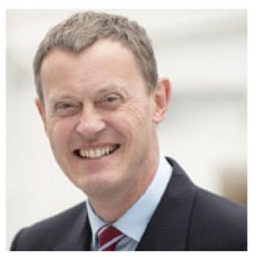

Dr. Pennell

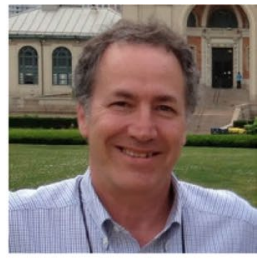

Dr. Kellman

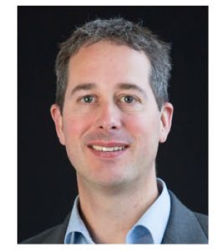

Dr. Petersen

Fig. 22020 JCMR 14th Gerald M. Pohost Awardee/runner up. 3rd Dudley Pennell Awardee/runner-up

editor-in-chief. In 2006, he was succeeded by Professor Dudley Pennell (Fig. 2) of the Royal Brompton Hospital, London, England. Since December 2016, the JCMR editorial office has been located at the Beth Israel Deaconess Medical Center, Boston, Massachusetts, USA under my leadership. My 6 year term will end at the end on December 31, 2022, and I have decided not to request a second term. My decision was based on numerous personal and professional issues and does not reflect any decline in my passion for CMR or the JCMR. The JCMR associate editors, journal club editors, and SCMR leadership have been aware of my decision for several months-with plans underway to identify my successor. I anticipate a new JCMR editor-in-chief will be selected by the SCMR leadership in the coming months and our Boston team will work towards a smooth transition at the end of 2022 with closure of the Boston office in April 2023. If you are interested in the editor-in-chief role, I suggest that you contact SCMR leadership!

\section{JCMR editorial and management team}

The JCMR Associate Editors (Table 1) reflect the international and diverse spectrum of the SCMR. This past year, Dr. Tim Leiner returned to the associate editorial board after stepping away during his term as president of the International Society of Magnetic Resonance in Medicine (ISMRM). It is great to have Tim's wisdom back at our weekly editorial board meetings. Drs. Yuchi Han and Tim Leiner didn't miss a beat of their JCMR associate editorial participation despite their professional moves this year to Ohio State University and the Mayo Clinic, respectively. Our other Associate Editors include Drs. Rene Botnar (UK/Chile), John Greenwood (UK), Dara Kraichman
Table 1 JCMR Associate Editors, Statistical Editor, Journal Club Editors, and Social Media Editors

\begin{tabular}{ll}
\hline Associate Editors & \\
Rene Botnar & King's College, London, UK/Chile \\
John Greenwood & University of Leeds, UK \\
Yuchi Han & Ohio State University, USA \\
Dara Kraichman & Johns Hopkins University School of Medicine, USA \\
Robert Ledeerman & National Institutes of Heart, Lung, and Blood \\
& Institute, USA \\
Tim Leiner & Mayo Clinic, USA \\
Reza Nezafat & Beth Israel Deaconess Medical Center, USA \\
Amit Patel & University of Virginia, USA \\
Joshua Robinson & Northwestern University, USA \\
Connie Tsao & Beth Israel Deaconess Medical Center, USA \\
Statistical Editor & \\
Long Ngo & Beth Israel Deaconess Medical Center, USA \\
Journal Club Editors & \\
Scott Flamm & Cleveland Clinic, USA \\
Raymond Kwong & Brigham and Women's Hospital, USA \\
Matthias Stuber & University of Lausanne, Switzerland \\
Social Media Editors & \\
Juan Lopez-Mattei & Lee Health Heart, USA \\
Purvi Parwani & Loma Linda University Health, USA \\
\hline
\end{tabular}

(USA), Robert Lederman (USA), Reza Nezafat (USA), Amit Patel (USA), Joshua Robinson (USA) and Connie Tsao (USA). Dr. Long Ngo (USA) continues to serve as our statistical editor. Drs. Juan Lopez-Mattei (USA) and Purvi Parwani (USA) are busy every week disseminating $J C M R$ news as our Social Media/Twitter editors. 
Jennifer Rodriguez (jcmroffice@scmr.org) joined the $J C M R$ managing staff as an assistant managing editor in mid-2019 and was promoted to managing editor in January 2021 (Fig. 3). Jennifer has made tremendous progress in keeping me and the entire manuscript review process organized and on schedule. As a result, we have seen a marked decrease in our time to first decision time from a mean of 63 days in 2019 to 36 days for the first 6 months of 2021! I hope our authors have felt this tangible difference.

\section{JCMR Journal Club}

A highlight of 2020 was the introduction of our JCMR Journal Club just as the COVID-19 pandemic was bursting across the globe in March 2020. These monthly one-hour webinars are held on the 2nd Wednesday of the month at 11am ET. A link for the monthly registration is on the JCMR (https://jcmr-online.biomedcent ral.com/) and SCMR (www.scmr.org) websites. These monthly JCMR Journal Clubs are hosted by one of our three Journal Club Editors, Drs. Scott Flamm (clinical), Raymond Kwong (clinical) and Matthias Stuber (nonclinical). On a rotating basis, each editor choses a manuscript that was recently published in JCMR After a brief Journal Club Editor introduction of the topic, the presenting author gives a 25-30 min presentation followed by a spirited $30 \mathrm{~min}$ discussion. We continue to offer CME for reading the manuscript and hope to provide CME for Journal Club attendance in the coming year. Please join $>100$ of your colleagues every month for an informative presentation and discussion! Don't worry if you missed one. Recordings of the monthly webinars and a CME link are provided on the SCMR web site. Check them out!

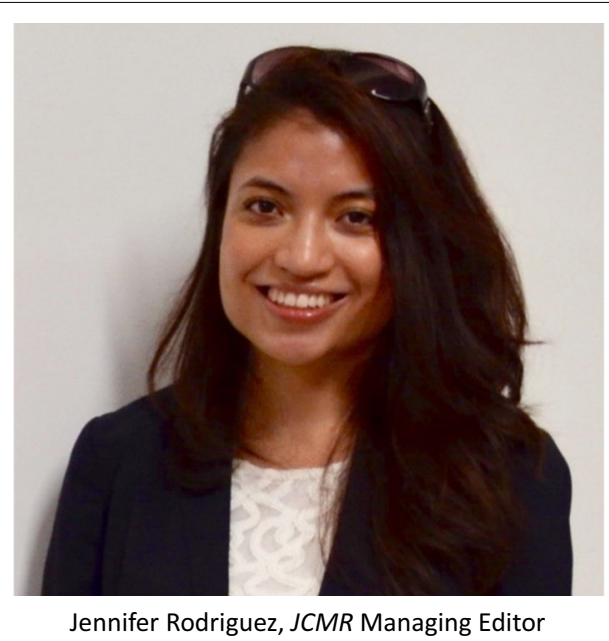

Fig. 3 Jennifer Rodriguez is the JCMR managing editor
Like other JCMR activities, the JCMR Journal Club is a village effort. In addition to our 3 talented Journal Club editors, I very much appreciate the strong administrative assistance of Lauren Small from the SCMR managing office who was succeeded by Sarah Mania this past July. Lauren and now Sarah are responsible for coordinating registration, the speaker presentations, CME, Zoom operations and recording, and subsequent posting of the monthly JCMR Journal Club recording on the SCMR website. The 2020 JCMR Journal Club selections were on a wide variety of topics (Table 2).

\section{Manuscript review process, omissions, and suggestions}

I reviewed the manuscript submission process in my report last year [1] and will further expand on this below.

All manuscripts are submitted and processed through the http://www.jcmr-online.org website. I encourage all authors to closely follow the guidelines so as not to delay the review process. By far, the most error that leads to review delay is the omission of the names and contact information for at least two suggested reviewers in the cover letter. I ask authors to use JCMR preferred abbreviations (https://jcmr-online.biomedcentral.com/submi ssion-guidelines/preparing-your-manuscript/abbreviati ons) and to use the terms "CMR" and "cardiovascular magnetic resonance" rather than "cardiac magnetic resonance." While the abbreviation issue does not delay the review, it adds additional burden to the prepublication editing process.

I encourage authors to carefully consider the number of significant digits and reported p values in their manuscripts. For example, when reporting native $\mathrm{T} 1$ and standard deviation, would report to the nearest $\mathrm{ms}$ and not to the X.X ms or X.XX ms. While technically accurate, reporting $\mathrm{T} 1$ to this level of accuracy has no clinical relevance. Similarly, when reporting p values for the sample sizes of most JCMR publications, a value of $<0.001$ is a reasonable limit.

JCMR subscribes to the BMC guidelines for manuscript citations (https://www.biomedcentral.com/getpu blished/editorial-policies\#citations) which I will summarize below.

Research articles and non-research articles (e.g. Reviews and Position Papers) should cite appropriate and relevant literature in support of the claims made. Excessive self-citation, coordinated efforts among authors to collectively self-cite, gratuitous and unnecessary article citation or any other form of citation manipulation are inappropriate and strongly discouraged.

Authors should consider the following guidelines when preparing their manuscript: 
Table 22020 Monthly JCMR Journal Club Editor, Presenter, Manuscript

\begin{tabular}{|c|c|c|c|}
\hline Date & Editor & Presenter & Manuscript \\
\hline $3 / 10 / 2020$ & Raymond Kwong & Mohammad Alkhalil & $\begin{array}{l}\text { Hyper-acute cardiovascular magnetic resonance T1 mapping predicts infarct char- } \\
\text { acteristics in patients with ST elevation myocardial infarction. [20] }\end{array}$ \\
\hline $4 / 15 / 2020$ & Scott Flamm & Thu-Thao Le & $\begin{array}{l}\text { The application of exercise stress cardiovascular magnetic resonance in patients } \\
\text { with suspected dilated cardiomyopathy. [22] }\end{array}$ \\
\hline $5 / 13 / 2020$ & Raymond Kwong & Haikun Qi & $\begin{array}{l}\text { Respiratory motion-compensated high-resolution 3D whole-herat T1p mapping. } \\
\text { [23] }\end{array}$ \\
\hline $6 / 10 / 2020$ & Scott Flamm & G.J.H. Snel & $\begin{array}{l}\text { Cardiovascular magnetic resonance native } \mathrm{T} 2 \text { and } \mathrm{T} 2^{*} \text { quantitative values for cardio- } \\
\text { myopathies and heart transplantations: a systematic review and meta-analysis. [5] }\end{array}$ \\
\hline $7 / 8 / 2020$ & Matthias Stuber & Adrienne E. Campbell-Washburn & A comparison of cine CMR imaging at 0.55 T and 1.5 T. [15] \\
\hline $8 / 12 / 2020$ & Raymond Kwong & Eike Nagel & $\begin{array}{l}\text { Sub-segmental quantification of single (stress)-pass perfusion CMR improves the } \\
\text { diagnostic accuracy for detection of obstructive coronary artery disease. [27] }\end{array}$ \\
\hline $9 / 16 / 2020$ & Scott Flamm & B. Domenech-Ximenos & $\begin{array}{l}\text { Prevalence and pattern of cardiovascular magnetic resonance late gadolinium } \\
\text { enhancement in highly trained endurance athletes. [28] }\end{array}$ \\
\hline $10 / 14 / 2020$ & Raymond Kwong & Amol S. Pednekar & $\begin{array}{l}\text { Breath-hold and free-breathing quantitative assessment of biventricular volume } \\
\text { and function using compressed SENSE: a clinical validation in children and young } \\
\text { adults. [32] }\end{array}$ \\
\hline $11 / 11 / 2020$ & Matthias Stuber & Thomas P. Craven & $\begin{array}{l}\text { Exercise cardiovascular magnetic resonance development, current utility, and future } \\
\text { applications. [3] }\end{array}$ \\
\hline $12 / 8 / 2020$ & Scott Flamm & Teresa Correia and Claudia Prieto & $\begin{array}{l}\text { Accelerated high-resolution free-breathing 3D whole-heart T2-prepared black- } \\
\text { blood and bright-blood CMR. [33] }\end{array}$ \\
\hline
\end{tabular}

Continuing medical education (CME) is offered for reading of the manuscript and is a complimentary benefit for SCMR members

- Statements that rely on external sources of information (i.e. not the authors' own new ideas or findings or general knowledge) should use a citation.

- Authors should cite the original work rather than a review article that cites an original work.

- Authors should ensure that their citations are accurate.

- Authors should not cite sources that they have not read.

- Authors should cite the most appropriate publication and not preferentially cite their own or their friends', peers', or institution's publications.

- Authors should avoid citing work solely from one country.

- Authors should not use an excessive number of citations to support one point.

- When possible, authors should prioritize peerreviewed sources and should not cite advertisements or advertorial material.

After manuscript submission and BMC office confirmation that the manuscript is in the appropriate format (abstract, text, references, figures, tables, supplements), the manuscript is sent to the Boston office for initial review. Within 48 business hours, I assess the manuscript for its appropriateness for the JCMR readership and its overall likely priority for publication. Approximately $5 \%$ of submitted manuscripts are deemed inappropriate for the JCMR audience (non-CMR topic) or very unlikely to reach sufficient priority for acceptance (e.g., case reports/ very small case series, unsolicited reviews). These manuscripts are quickly returned to the author(s) so as to expedite submission to a more appropriate journal. If appropriate, the authors are offered the opportunity to directly forward their manuscript to another BMC openaccess publication.

For manuscripts deemed appropriate for consideration, an associate editor is assigned and reviewer assignments are then requested. Manuscript evaluations are simultaneously requested from up to 5 reviewers (with special consideration for the 2 author suggested reviewers) until confirmed acceptance has been received by 3 reviewers. Reviewers are asked to follow a specific format and to return their review within 2 weeks of acceptance. We are fortunate to have over 900 reviewers (but are always looking to expand our reviewer pool and encourage all members/innovators/leaders of the CMR field to apply to be a reviewer. If you are interested in becoming a $J C M R$ reviewer, please contact our managing editor, Jennifer Rodriguez at jcmroffice@scmr.org.

When at least two (of 3 agreed) reviews have been received by noon Friday, the manuscript is scheduled for discussion at our weekly associate editorial board meeting held every Tuesday from 9:30 to 10:30 a.m. ET. When I am out of town/unavailable, the associate editors continue to meet so as to not delay the publication process. At each meeting, 4-12 manuscripts may be discussed. The manuscript decisions at that meeting include. 
1. Accept (most commonly after one or more major and/or minor revisions)

2. Minor revision-No new experiments are requested, relatively minor text changes or analyses are requested; 30 day turn-around with submission of clean and track-change versions of the manuscripts along with point-by-point response(s) to the reviewers/editors. These manuscripts are generally not returned to the reviewers for their assessment. We expect $>98 \%$ acceptance.

3. Major revision-Substantial text and/or analyses are needed. This may include additional experiments; 90 day turn-around with submission of clean and track-change versions of the manuscripts along with point-by-point responses to the reviewers/editors. These manuscripts are sent back to the original reviewers to confirm that their concerns have largely been addressed. Overall, 60\% ultimate acceptance is anticipated

4. Denovo resubmission-Substantial new experiments/ analyses are needed or change in manuscript focus; unlimited turn-around time with submission of clean and track-change versions of the manuscripts along with point-by-point responses to the reviewers/editors. These manuscripts are usually sent to the original reviewers to confirm their concerns have been addressed. Overall, we anticipate $\sim 40 \%$ acceptance.

5. Decline Authors are offered the opportunity to have their manuscript considered by another journal in the BMC family with inclusion of the JCMR reviews to expedite the process.

When a manuscript is accepted, I then edit the submission to be consistent with JCMR style/abbreviations (see https://jcmr-online.biomedcentral.com/submi ssion-guidelines/preparing-your-manuscript/abbreviati ons) before final submission to BMC for galley production. The galleys are first sent to the corresponding author and finally to me for final sign-off. I then identify a postage stamp (remember those!) image for publication in $J C M R$ web site listing and to accompany the @ JournalofCMR twitter feed. The manuscript is usually published on-line within a week of my final sign-off. Along with BMC, Drs. Juan Lopez-Mattei and Purvi Parwani handle the social media dissemination of the manuscript's publication.

Upon taking my position as editor-in-chief in 2017, my goal was to have first decision within 40 days of receipt for $60 \%$ of manuscripts, a process that is dependent on timely return of reviews. I am pleased to report that we have more than achieved this goal for 2021-thanks in large part to the strong efforts of our new managing editor, Jennifer Rodriguez. Delays are due to multiple issues-if the two reviews markedly differ in their assessment/recommendation ( $\sim 25 \%$ of the time) or the associate editor feels we need additional information; we may then delay a decision until the third review has been received or solicit a fourth. We may also to seek the counsel of our statistical reviewer, Dr. Long Ngo. If any of these occur, we try to alert the corresponding author.

We recognize that the review process is not perfect. We may not have sent the manuscript to the best reviewers (your suggestions help, or the best reviewers may have declined our invitation). The reviewer may have misinterpreted the manuscript (we try to catch this at our weekly associate editorial meeting).

Sometimes you will find the editorial decision is different from your perception of the review(s). This is because we do our best to objectively assess the science, presentation, and appropriateness for the JCMR audience. The review(s) help, but we also ask ourselves these four questions:

1. Is the study scientifically sound?

2. Are the Methods, Results, and Discussion appropriately presented?

3. Is the work novel? Does the study extend or clarify our current understanding or is it a confirmation of a prior report?

4. Will our readership be interested or informed by the topic?

Anonymized reviews are returned to the authors. We continue to work with BMC so that we can post anonymized reviews for published manuscripts on the $J C M R$ web site. In contrast to some open-access journals, I do not anticipate posting of submitted (but not accepted) manuscripts or inclusion of prior versions of an accepted manuscript as I am concerned such postings will be confusing to the reader. Stay tuned as we hopefully bring you anonymized reviews in 2022.

\section{All manuscripts submitted to the journal cannot be under simultaneous consideration by another journal}

All work submitted to the JCMR must be original and cannot be under consideration by another journal until a decision is made by the JCMR. Fortunately, this past year we have not had any known occurrence of simultaneous submissions; but have unfortunately become aware of this issue in the past. When this does occur, the manuscript is immediately withdrawn from further consideration and the authors are put on administrative warning. 
Table 32020 JCMR Gold Star Reviewers listed in alphabetical order by last name.

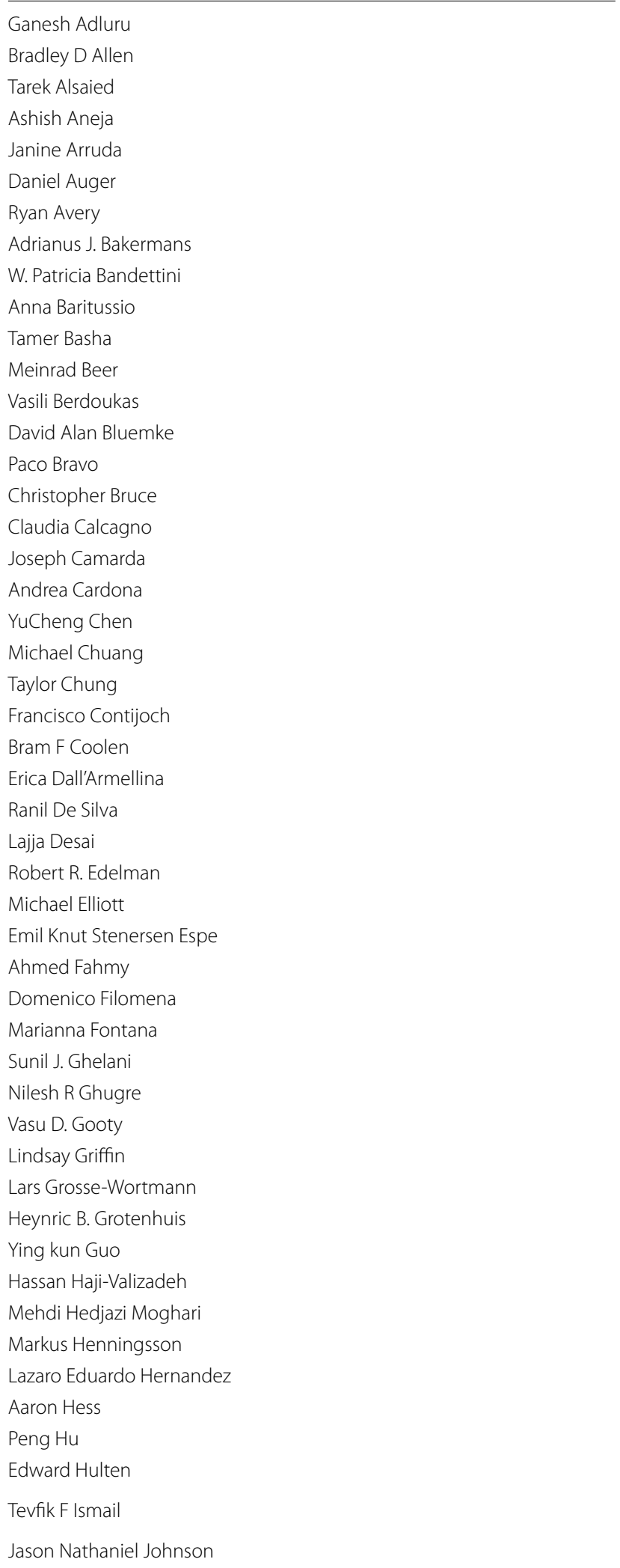

Table 3 (continued)

Jennifer Jordan

Shingo Kato

Keigo Kawaji

Won Yong Kim

Gert Klug

Grigorios Korosoglou

Sebastian Kozerke

Ramkumar Krishnamurty

Selcuk Kucukseymen

Deborah Kwon

Seung-Pyo Lee

Zhitao Li

Timo Liimatainen

Joao A.C. Lima

Harold Litt

Massimo Lombardi

Jimmy Lu

Minjie Lu

Julian Luetkens

Pierre-Yves Marie

Michael Markl

Shiraz Maskatia

Anthony MerloccoLorenzo Monti

Vivek Muthurangu

Shintaro Nakano

Thomas Neuberger

Christopher Nguyen

TD Nguyen

Laura Olivieri

Declan O'Regan

Ellen Ostenfeld

Paras Parikh

Dana Peters

Steffen E Petersen

Prashob Porayette

Valentina O Puntmann

Francesca Raimondi

Shams Rashid

Nathaniel Reichek

Pierangelo Renella

Jose F Rodriguez Palomares

Idan Roifman

Frederick Ruberg

Tobias Rutz

Sudip Saha

Hajime Sakuma

Michael Schär

Ehud Schmidt

Andrew David Scott

Aurelio Secinaro 
Table 3 (continued)

\begin{tabular}{l} 
Dipan J. Shah \\
Moneal Shah \\
Sujata M Shanbhag \\
Gaurav Sharma \\
Chetan Shenoy \\
Timothy Slesnick \\
Sahar Soleimani \\
Monvadi Barbara Srichai-Parsia \\
Jordan B. Strom \\
Matthias Stuber \\
Avan Suinesiaputra \\
Qian Tao \\
Michael D. Taylor \\
Connie Tsao \\
Robert Tunks \\
Pim van Ooij \\
Akos Varga-Szemes \\
Miguel Silva Vieira \\
Inga Voges \\
Maximilian von Roeder \\
RalfWassmuth \\
Sebastian Weingärtner \\
David Wendell \\
Jos J Westenberg \\
John Whitaker \\
Timothy C Wong \\
Pamela Woodard \\
Katherine Wu \\
Yibin Xie \\
Hsin-Jung Yang \\
Yang Yang \\
Alistair Young \\
Chun Yuan \\
Karolina Zareba \\
Chengcheng Zhu \\
\hline
\end{tabular}

\section{Reviewer recognition-Gold Star Reviewers}

Reviewers are a key component to the success of the JCMR. As a recognition of reviewers, at the 2021 SCMR Annual meeting we recognized our 135 "Gold Star" Reviewers for 2020 (Table 3). Gold Star reviewers are those individuals who reviewed at least $3 J C M R$ manuscripts in 2020, with reviews both of high quality and timeliness. Please join the ranks of JCMR reviewers and strive to be a Gold Star reviewer! As an added incentive, reviewers have the option to receive continuing medical education (CME) credit for providing a review.

\section{Conflict-of-interest, reviews, SCMR guideline/ position manuscripts and SCMR Committee papers}

Conflict-of-interest manuscripts, those for which a member of the associate editorial board is either an author or closely associated with an author, are independently handled by a Guest Editor (Table 4) chosen by me. Neither I nor any of the associate editorial board are involved with reviewer selection or with manuscript decision. Our managing editorial office assists the Guest Editor with the administrative software/Editorial Manager. If a conflict-of-interest manuscript is accepted, the Guest Editor is recognized in the JCMR publication with the text "Dr. XX served as a JCMR Guest Editor for this manuscript."

The JCMR does not accept unsolicited reviews. Authors are encouraged to contact me before submitting any reviews. In general, reviews are authored by individuals considered experts in the field and receive considerable attention/downloads. All solicited reviews follow the usual peer-review process. Several reviews were published in 2020 (Table 5), including reviews on normative values [2] exercise CMR [3], native T2 and T2* for cardiomyopathies and heart transplantation $[4,5]$, the role of CMR in women [6], and highlights of the $202023^{\text {rd }}$ SCMR Scientific Session [7].

The JCMR is the official publication of the SCMR. As such, SCMR Guidelines and Position papers endorsed by the Full (or Executive) SCMR Board(s) do not undergo peer review. I review these manuscripts for consistency with $J C M R$ style and abbreviations. They are then published in an expeditious manner. In addition to Society Position papers on standardized image interpretation and post-process [8], updated standardized CMR protocols [9], and clinical indications for CMR [10], we published several Covid-specific SCMR position papers in $2020[11,12]$ (Table 5). I have encouraged Society leadership to have updates of the Guideline papers to be on a 5 year renewal cycle, with rotation in authorship as well. In contrast to SCMR Guidelines and Position papers, SCMR Committee approved manuscripts undergo the usual JCMR peer review process albeit with an anticipation that they will ultimately be published in the JCMR. SCMR Committee publications in 2020 are listed in Table 5.

\section{SCMR case of the week series}

While the JCMR does not accept case reports, for many years, the SCMR web site has an active "Case of the Week" (https://scmr.org/page/caseoftheweekLDGPG) series, currently coordinated by Dr. Sylvia Chen. In 2021, we published the 2019 Case series as a single manuscript [13]. We plan to make this unified publication an annual occurrence in JCMR to allow for these illustrative cases to be more widely available to search engines. 
Table 42020 JCMR Guest Editors

\begin{tabular}{ll}
\hline Andrew E. Arai & USA \\
Hugh Calkins & Johns Hopkins University, USA \\
Raymond Chan & University of Toronto, Canada \\
Paul Finn & University of California at Los Angeles, USA \\
Matthias Gero Friedrich & McGill University, Canada \\
Robert Judd & Duke University, USA \\
Tim Leiner & Utrecht University, The Netherlands \\
Debiao Li & Cedars-Sinai Medical Center, USA \\
Daniel R. Messroghli & Charité-University Medicine Berlin, Germany \\
John Oshinski & Emory University, USA \\
Ellen Ostenfeld & Lund University, Sweden \\
Nathaniel Reichek & Stony Brook University, USA \\
Matthias Stuber & University of Lausanne, Switzerland \\
Robert Weiss & Johns Hopkins University, USA
\end{tabular}

Table 52020 JCMR Reviews and SCMR Position Statements

\begin{tabular}{|c|c|}
\hline First author & Publication \\
\hline \multicolumn{2}{|l|}{2020 JCMR reviews } \\
\hline Craven et al. & $\begin{array}{l}\text { Exercise cardiovascular magnetic resonance: development, current utility } \\
\text { and future applications.* [3] }\end{array}$ \\
\hline Snel GJH et al. & $\begin{array}{l}\text { Cardiovascular magnetic resonance native } \mathrm{T} 2 \text { and } \mathrm{T} 2^{*} \text { quantitative values } \\
\text { for cardiomyopathies and heart transplantations: a systematic review and } \\
\text { meta-analysis. }[4,5]\end{array}$ \\
\hline Bucciarelli-Ducci, et al. & $\begin{array}{l}\text { Cardiovascular disease in women: insights from magnetic resonance imag- } \\
\text { ing. [6] }\end{array}$ \\
\hline Grosse-Wortman, et al. & $\begin{array}{l}\text { Highlights of the } 2020 \text { 23rd Society for Cardiovascular Magnetic Resonance } \\
\text { Scientific Sessions. [7] }\end{array}$ \\
\hline Kawel-Boehm et al. & $\begin{array}{l}\text { Reference ranges ("normal values") for cardiovascular magnetic resonance } \\
\text { (CMR) in adults and children: } 2020 \text { update. [2] }\end{array}$ \\
\hline \multicolumn{2}{|l|}{2020 SCMR position papers } \\
\hline Schulz-Menger et al. & $\begin{array}{l}\text { Standardized image interpretation and post-processing in cardiovascular } \\
\text { magnetic resonance-2020 update: Society for Cardiovascular Magnetic } \\
\text { Resonance (SCMR): Board of Trustees Task Force on Standardized Post- } \\
\text { Processing. [8] }\end{array}$ \\
\hline Kramer et al. & $\begin{array}{l}\text { Standardized cardiovascular magnetic resonance imaging (CMR) protocols: } \\
2020 \text { update. [9] }\end{array}$ \\
\hline Leiner et al. & $\begin{array}{l}\text { SCMR Position Paper (2020) on clinical indications for cardiovascular mag- } \\
\text { netic resonance. [10] }\end{array}$ \\
\hline Allen et al. & $\begin{array}{l}\text { Society for Cardiovascular Magnetic Resonance (SCMR) guidance for re- } \\
\text { activation of cardiovascular magnetic resonance practice after peak phase } \\
\text { of the COVID-19 pandemic. [12] }\end{array}$ \\
\hline Han et al. & $\begin{array}{l}\text { Society for Cardiovascular Magnetic Resonance (SCMR) guidance for } \\
\text { the practice of cardiovascular magnetic resonance during the COVID-19 } \\
\text { pandemic. [11] }\end{array}$ \\
\hline
\end{tabular}

* CME offered for this manuscript

\section{Continuing Medical Education (CME) JCMR Journal Club}

For over 4 years we have been offering on-line CME credit for the benefit of our clinician readers and is a free benefit for SCMR members - allowing them to more easily fulfill the CME criteria for maintenance of their Level
II or III certification [14]. This program has been a great success and was greatly expanded with 20 manuscripts in 2020 alone! (Table 6). Please see http://scmr.peachnewme dia.com/store/provider/custompage.php?pageid $=20$ for the complete listing. 
Table 62020 JCMR manuscripts chosen for continuing medical education (CME)

\begin{tabular}{|c|c|}
\hline Dreisbach et al. & $\begin{array}{l}\text { Cardiovascular magnetic resonance based diagnosis of left ventricular non-compaction cardiomyopathy: Impact of cine } \\
\text { bSSFP strain analysis. [19] }\end{array}$ \\
\hline Alkhalil et al. & $\begin{array}{l}\text { Hyper-acute cardiovascular magnetic resonance T1 mapping predicts infarct characteristics in patients with ST } \\
\text { elevation myocardial infarction. [20] }\end{array}$ \\
\hline Bandettini et al. & A comparison of cine CMR imaging at $0.55 \mathrm{~T}$ and $1.5 \mathrm{~T}$. [15] \\
\hline Kim et al. & $\begin{array}{l}\text { Myocardial structural and functional changes in patients with liver cirrhosis awaiting liver transplantation: A comprehensive } \\
\text { cardiovascular magnetic resonance and echocardiographic study. [21] }\end{array}$ \\
\hline Le et al. & $\begin{array}{l}\text { The application of exercise stress cardiovascular magnetic resonance in patients with suspected dilated cardio- } \\
\text { myopathy. [22] }\end{array}$ \\
\hline Qi et al. & Respiratory motion-compensated high-resolution 3D whole-heart t1p mapping. [23] \\
\hline Holtstiege et al. & $\begin{array}{l}\text { Clinical experience regarding safety and diagnostic value of cardiovascular magnetic resonance in patients with a subcuta- } \\
\text { neous implanted cardioverter/defibrillator (S-ICD) at 1.5 T. [24] }\end{array}$ \\
\hline Snel et al. & $\begin{array}{l}\text { Cardiovascular magnetic resonance native } \mathrm{T} 2 \text { and } \mathrm{T} 2^{*} \text { quantitative values for cardiomyopathies and heart trans- } \\
\text { plantations: a systematic review and meta-analysis. }[4,5]\end{array}$ \\
\hline Podlesnikar et al. & $\begin{array}{l}\text { Left ventricular functional recovery of infarcted and remote myocardium after ST-Segment elevation myocardial infarction } \\
\text { (METOCARD-CNIC randomized clinical trial substudy. [25] }\end{array}$ \\
\hline Backhaus et al. & $\begin{array}{l}\text { Real-time cardiovascular magnetic resonance T1 and extracellular volume fraction mapping for tissue characterisation in } \\
\text { aortic stenosis. [26] }\end{array}$ \\
\hline Le et al. & $\begin{array}{l}\text { Sub-segmental quantification of single (stress)-pass perfusion CMR improves the diagnostic accuracy for detec- } \\
\text { tion of obstructive coronary artery disease. [27] }\end{array}$ \\
\hline Domenech-Ximenos et al. & $\begin{array}{l}\text { Prevalence and pattern of myocardial late enhancement in cardiac magnetic resonance of highly trained endur- } \\
\text { ance athlete. [28] }\end{array}$ \\
\hline Xu et al. & $\begin{array}{l}\text { Multiparametric cardiovascular magnetic resonance characteristics and dynamic changes in myocardial and skeletal mus- } \\
\text { cles in idiopathic inflammatory cardiomyopathy. [29] }\end{array}$ \\
\hline Kato et al. & $\begin{array}{l}\text { Incremental prognostic value of coronary flow reserve determined by phase-contrast cine cardiovascular magnetic reso- } \\
\text { nance of the coronary sinus in patients with diabetes mellitus. [30] }\end{array}$ \\
\hline Liu et al. & $\begin{array}{l}\text { Myocardial fibrosis in asymptomatic and symptomatic severe chronic primary mitral regurgitation and relationship to tissue } \\
\text { characterization and LV function on cardiovascular magnetic resonance. [31] }\end{array}$ \\
\hline Kocaoglu et al. & $\begin{array}{l}\text { Breath-hold and free-breathing quantitative assessment of biventricular volume and function using compressed } \\
\text { SENSE: a clinical validation in children and young adults. [32] }\end{array}$ \\
\hline Craven et al. & Exercise cardiovascular magnetic resonance: development, current utility and future applications. [3] \\
\hline Correia et al. & $\begin{array}{l}\text { Accelerated high-resolution free-breathing 3D whole-heart T2-prepared black-blood and bright-blood cardiovas- } \\
\text { cular magnetic resonance. [33] }\end{array}$ \\
\hline Xu et al. & Layer-specific strain in patients with heart failure using cardiovascular magnetic resonance: not all layers are the same. [32] \\
\hline Pennig et al. & $\begin{array}{l}\text { Clinical application of free-breathing 3D whole heart late gadolinium enhancement cardiovascular magnetic resonance } \\
\text { with high isotropic spatial resolution using Compressed SENSE. [35] }\end{array}$ \\
\hline
\end{tabular}

Bold manuscripts were also selected for 2020 JCMR Journal Club presentation

\section{Social media}

I am very much a social media novice, but the JCMR continues to be very active on Twitter with the handle "Journal of CMR." Tweets go out with the publication of each manuscript publication and announcing each Journal Club. This activity is coordinated by our two Social Media editors, Drs. Juan Lopez-Mattei and Purvi Parwani. According to Dr. Parwani and Lopez-Mattei, as of $12 / 21 / 2021$, we had 3830 followers (a 20\% increase over last year). For comparison, the Journal of the American Society of Echocardiography (JASE) has 3301 followers, the Journal of Cardiac Computed Tomography (JCCT) has 3226 followers, Circulation: Cardiovascular Imaging has 2603 followers, and the Journal of Nuclear Cardiology has 1480 followers. We thank our Twitter audience for the strong \#whyCMR following.

\section{Gerald M. Pohost and Dudley Pennell Awards}

In recognition of the efforts of our inaugural editor-inchief, Dr. Gerald M. Pohost, (Fig. 2) for the past 14 years, the JCMR has awarded the Pohost Prize to that manuscript deemed by the associate editors and editorial board to be the best/most important manuscript published in the prior year. The associate editors and I select the Pohost finalists (Table 7) and the entire editorial board votes on the top prize. At the virtual 2021 SCMR Scientific Sessions annual meeting, the 14th Gerald M. Pohost Prize was awarded to Dr. Bandettini (Fig. 3) and co-workers for their manuscript" A comparison of cine CMR imaging at $0.55 \mathrm{~T}$ and $1.5 \mathrm{~T}$ " [15]. The Pohost Runner-up Prize was awarded to Dr. Reddy (Fig. 3) and colleagues for their publication, "Invasive cardiovascular magnetic resonance (iCMR) for diagnostic right and left 
Table 72021 Gerald M. Pohost Award Finalists. Dr. Bandettini was the recipient of the 14th Gerald M. Pohost Award. Dr. Reddy was the runner-up

\begin{tabular}{|c|c|}
\hline Bandettini et al. & A comparison of cine CMR imaging at 0.55 T and 1.5 T. [15] \\
\hline Champ-Rigot et al. & $\begin{array}{l}\text { Clinical outcomes after primary prevention defibrillator implantation are better predicted when the left ventricular ejection frac- } \\
\text { tion is assessed by cardiovascular magnetic resonance. [36] }\end{array}$ \\
\hline Jacobs et al. & $\begin{array}{l}\text { Direct measurement of atrioventricular valve regurgitant jets using 4D flow cardiovascular magnetic resonance is accurate and } \\
\text { reliable for children with congenital heart disease: a retrospective cohort study. [37] }\end{array}$ \\
\hline Kranzusch et al. & $\begin{array}{l}\text { Z-score mapping for standardized analysis and reporting of cardiovascular magnetic resonance modified Look-Locker inversion } \\
\text { recovery (MOLLI) T1 data: Normal behavior and validation in patients with amyloidosis. [38] }\end{array}$ \\
\hline Lindemann et al. & $\begin{array}{l}\text { Clinical utility of cardiovascular magnetic resonance imaging in patients with implantable cardioverter defibrillators presenting } \\
\text { with electrical instability or worsening heart failure symptoms [39] }\end{array}$ \\
\hline Liu et al. & $\begin{array}{l}\text { Myocardial fibrosis in asymptomatic and symptomatic chronic severe primary mitral regurgitation and relationship to tissue char- } \\
\text { acterisation and left ventricular function on cardiovascular magnetic resonance. [31] }\end{array}$ \\
\hline Martini et al. & Deep learning to diagnose cardiac amyloidosis from cardiovascular magnetic resonance. [40] \\
\hline Olivieri et al. & $\begin{array}{l}\text { Normal right and left ventricular volumes prospectively obtained from cardiovascular magnetic resonance in awake, healthy, } \\
0-12 \text { year old children. [41] }\end{array}$ \\
\hline Qiao et al. & $\begin{array}{l}\text { Quantitative evaluation of carotid atherosclerotic vulnerable plaques using in vivo T1 mapping cardiovascular magnetic reson- } \\
\text { aonce: validation by histology. [42] }\end{array}$ \\
\hline Reddy et al. & $\begin{array}{l}\text { Invasive cardiovascular magnetic resonance (iCMR) for diagnostic right and left heart catheterization using an MR-conditional } \\
\text { guidewire and passive visualization in congenital heart disease. [16] }\end{array}$ \\
\hline
\end{tabular}

heart catheterization using an MR conditional guidewire and passive visualization in congenital heart disease" [16].

At that meeting, we also presented the 3rd Pennell Award in recognition of the foresight of JCMR's 2nd Editor-in-Chief, Professor Dudley J. Pennell (Fig. 2) to transition the JCMR to the open-access platform (a decision (spearheaded by then SCMR Publications Committee chairman, Dr. Matthias Friedrich). Their decision markedly improved JCMR's visibility and impact factor. The Pennell award is for that original manuscript that has most contributed to the Journal's impact factor for the calendar year 3 years prior to the award. The 3rd Dudley J. Pennell Prize was awarded to Dr. Petersen (Fig. 3) et al. for their publication, "Reference ranges for cardiac structure and function using cardiovascular magnetic resonance (CMR) in Caucasians from the UK Biobank population cohort" [17] with the runner-up Pennell Award was given to Dr. Peter Kellman (Fig. 3) and colleagues for publication, "Myocardial perfusion cardiovascular magnetic resonance: optimized dual sequence and reconstruction for quantification" [18].

Stay tuned for the 15th Pohost and 4th Pennell Awards that will presented at the 23nd Scientific Sessions of the Society this February!

\section{Tribute to Nathaniel Reichek}

This year the SCMR and the greater CMR community lost one of our founding fathers. Dr. Nathaniel Reichek (Fig. 4), a true giant in our field. Nat was literally "in the room" when the SCMR was founded, served as our 3rd president, was a 2017 recipient of the SCMR Gold Medal,

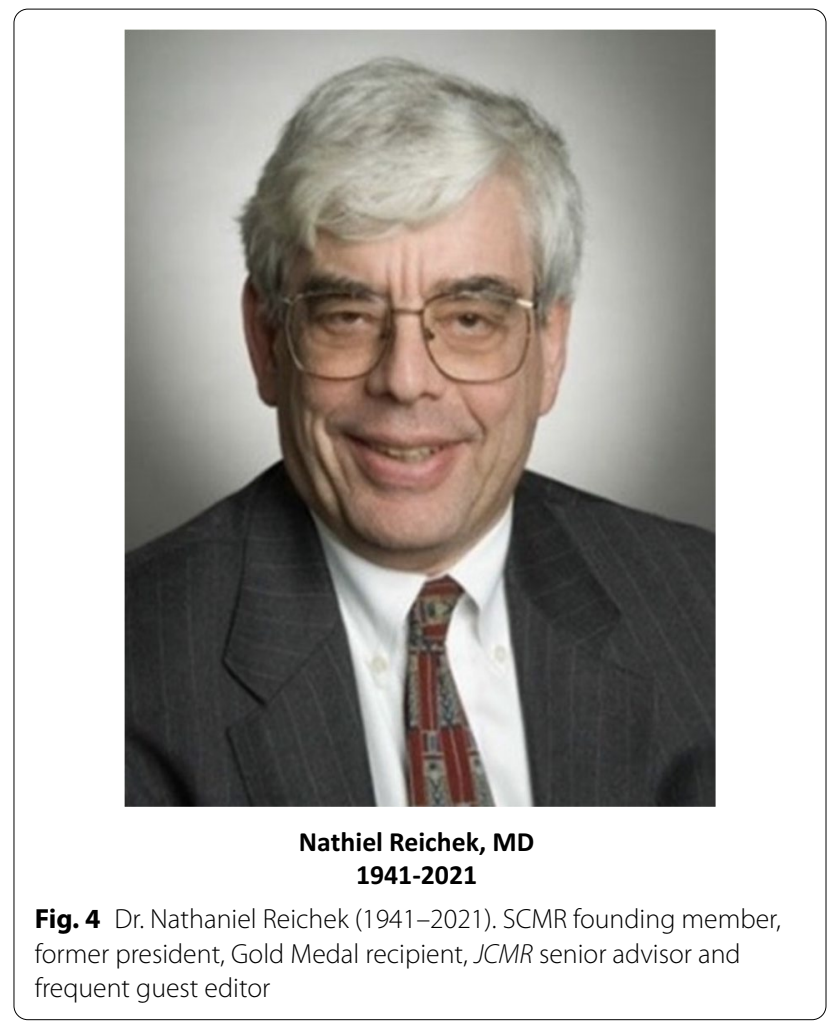

and for many years spearheaded the United States CMR Advocacy Committee. He was a very strong advocate and tireless worker for CMR, for the SCMR, and for the $J C M R$. I had the great personal privilege of knowing Nat for over 3 decades and will cherish our many discussions over the years. For my tenure as editor-in-chief, Nat was 

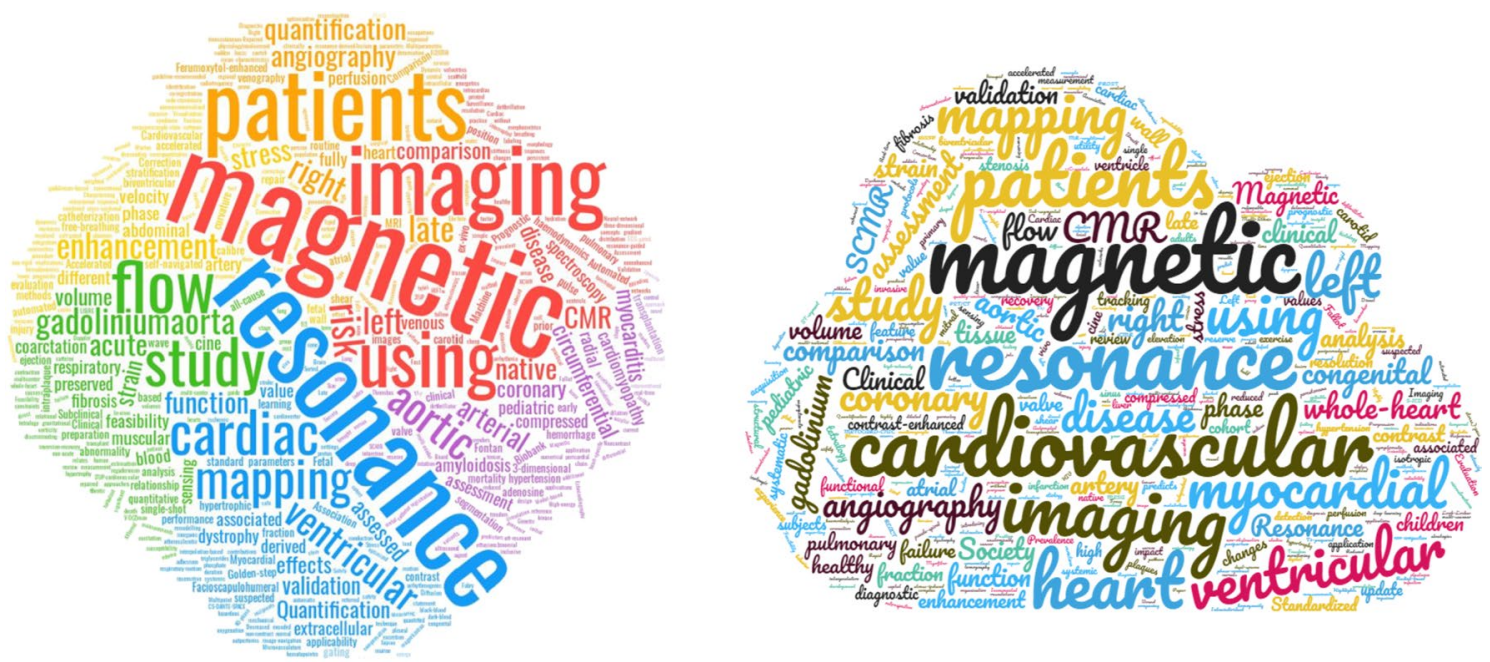

Fig. 5 WordCloud of A 2019 and B 2020 JCMR manuscript titles

my "go to" person for conflict-of-interest manuscripts. His command of CMR was almost unparalleled, and he readily gave his time to help the Journal and all who inquired of his opinion. While we didn't agree on every issue, Nat was a gentleman of high integrity, and I miss him at multiple levels. May his memory be for a blessing.

\section{Manuscripts-WordCloud}

As in last year's review, I again chose to create a Wordcloud (https://www.wordclouds.com) of the 2019 and 2020 JCMR titles (Fig. 5). As in 2019, the most common JCMR manuscript title words were magnetic, cardiovascular, resonance with 2020 followed by imaging, heart, ventricular and myocardial.

I hope you have found the annual "State of our $J C M R$ " informative. I remain your captain until December 2022, but as members of the $S C M R$, it is really your Journal for which I thank you for allowing me to provide stewardship. I close by again thanking the entire JCMR team and you, our readership. We will continue our efforts to maintain the average time-to-first decision to $<35$ days in 2022 and hope to be able to include anonymized reviewer comments with each manuscript. Remember to also join us for our monthly JCMR Journal Club for which I hope CME for attendance will be available later this year!

Wishing you a happy, healthy, and safe 2022. I am confident the brilliant scientific minds of our world will successfully get us through the COVID-19 pandemic, but like other disasters, we are unlikely to return to our preCovid state. Stay safe, advance the field of CMR, and take a moment to make sure that every day is special.

\section{Abbreviations}

APC: Article processing charge; CME: Continuing medical education; JCMR: Journal of Cardiovascular Magnetic Resonance; SCMR: Society for Cardiovascular Magnetic Resonance.

\section{Authors' contributions}

WJM is solely responsible for the contents of this review. The JCMR twitter statistics were provided by Dr. Purvi Parwani on 12/10/2020.

\section{Funding}

WJM receives an annual stipend from BMC for his role as JCMR editor-in-chief.

\section{Data availability}

Data sharing not applicable to this article as no datasets were generated or analyzed.

\section{Declarations}

Ethics approval and consent to participate

Not applicable.

\section{Consent for publication}

On request.

\section{Competing interests}

The author declares that they have no competing interests.

\section{Author details}

${ }^{1}$ Departments of Medicine (Cardiovascular Division) and Radiology, Beth Israel Deaconess Medical Center, Harvard Medical School, Boston, Massachusetts 02215, USA. ${ }^{2}$ JCMR Editorial Office, Boston, Massachusetts 02215, USA.

Received: 9 December 2021 Accepted: 14 December 2021

Published online: 04 March 2022

\section{References}

1. Manning WJ. 2020 - State of our JCMR. J Cardiovasc Magn Reson. 2021. https://doi.org/10.1186/s12968-020-00704-1.

2. Kawel-Boehm N, Hetzel SJ, Ambale-Venkatesh B, et al. Reference ranges ("normal values") for cardiovascular magnetic resonance (CMR) 
in adults and children: 2020 update. J Cardiovasc Magn Reson. 2020. https://doi.org/10.1186/s12968-020-00683-3.

3. Craven TP, Tsao CW, La Gerche A, et al. Exercise cardiovascular magnetic resonance: development, current utility and future applications. J Cardiovasc Magn Reson. 2020. https://doi.org/10.1186/ s12968-020-00652-w.

4. Snel GJH, van den Boomen M, Hernandez LM, et al. Correction to: cardiovascular magnetic resonance native $\mathrm{T}_{2}$ and $\mathrm{T}_{2}{ }^{*}$ quantitative values for cardiomyopathies and heart transplantations: a systematic review and meta-analysis. J Cardiovasc Magn Reson. 2020. https://doi.org/10 1186/s12968-020-00646-8.

5. Snel GJH, van den Boomen M, Hernandez LM, et al. Cardiovascular magnetic resonance native $T_{2}$ and $T_{2}^{*}$ quantitative values for cardiomyopathies and heart transplantations: a systematic review and meta-analysis. J Cardiovasc Magn Reson. 2020. https://doi.org/10.1186/ s12968-020-00627-x.

6. Bucciarelli-Ducci C, Ostenfeld E, Baldassarre LA, et al. Cardiovascular disease in women: insights from magnetic resonance imaging. J Cardiovasc Magn Reson. 2020. https://doi.org/10.1186/s12968-020-00666-4.

7. Grosse-Wortmann L, Francois CJ, Sierra-Galan LM, et al. Highlights of the 2020 23rd Society for Cardiovascular Magnetic Resonance Scientific Sessions. J Cardiovasc Magn Reson. 2020. https://doi.org/10.1186/ s12968-020-00672-6.

8. Schulz-Menger J, Bluemke DA, Bremerich J, et al. Standardized image interpretation and post-processing in cardiovascular magnetic resonance-2020 update. J Cardiovasc Magn Reson. 2020. https://doi.org/ 10.1186/s12968-020-00610-6.

9. Kramer CM, Barkhausen J, Bucciarelli-Ducci C, et al. Standardized cardiovascular magnetic resonance imaging (CMR) protocols: 2020 update. J Cardiovasc Magn Reson. 2020. https://doi.org/10.1186/ s12968-020-00607-1.

10. Leiner T, Bogaert J, Friedrich MG, et al. SCMR Position Paper (2020) on clinical indications for cardiovascular magnetic resonance. J Cardiovasc Magn Reson. 2020. https://doi.org/10.1186/s12968-020-00682-4.

11. Han Y, Chen T, Bryant J, et al. Society for Cardiovascular Magnetic Resonance (SCMR) guidance for the practice of cardiovascular magnetic resonance during the COVID-19 pandemic. J Cardiovasc Magn Reson. 2020. https://doi.org/10.1186/s12968-020-00628-w.

12. Allen BD, Wong TC, Bucciarelli-Ducci C, et al. Society for Cardiovascular Magnetic Resonance (SCMR) guidance for re-activation of cardiovascular magnetic resonance practice after peak phase of the COVID-19 pandemic. J Cardiovasc Magn Reson. 2020. https://doi.org/10.1186/ s12968-020-00654-8.

13. Johnson JN, Mandell JG, Christopher A, et al. Society for Cardiovascular Magnetic Resonance 2020 Case of the Week series. J Cardiovasc Magn Reson. 2021; 23(108).

14 Kim RJ, Simonetti OP, Westwood M, et al. Guidelines for training in cardiovascular magnetic resonance (CMR). J Cardiovasc Magn Reson. 2018. https://doi.org/10.1186/s12968-018-0481-8.

15. Bandettini WP, Shanbhag SM, Mancini C, et al. A comparison of cine CMR imaging at 0.55 T and 1.5 T. J Cardiovasc Magn Reson. 2020. https://doi. org/10.1186/s12968-020-00618-y.

16. Veeram Reddy SR, Arar Y, Zahr RA, et al. Invasive cardiovascular magnetic resonance (iCMR) for diagnostic right and left heart catheterization using an MR-conditional guidewire and passive visualization in congenital heart disease. J Cardiovasc Magn Reson. 2020. https://doi.org/10.1186/ s12968-020-0605-9.

17 Petersen SE, Aung N, Sanghvi MM, et al. Reference ranges for cardiac structure and function using cardiovascular magnetic resonance (CMR) in Caucasians from the UK Biobank population cohort. J Cardiovasc Magn Reson. 2017. https://doi.org/10.1186/s12968-017-0327-9.

18 Kellman P, Hansen MS, Nielles-Vallespin S, et al. Myocardial perfusion cardiovascular magnetic resonance: optimized dual sequence and reconstruction for quantification. J Cardiovasc Magn Reson. 2017. https://doi. org/10.1186/s12968-017-0355-5.

19 Dreisbach JG, Mathur S, Houbois CP, et al. Cardiovascular magnetic resonance based diagnosis of left ventricular non-compaction cardiomyopathy: impact of cine bSSFP strain analysis. J Cardiovasc Magn Reson. 2020. https://doi.org/10.1186/s12968-020-0599-3.
20 Alkhalil M, Borlotti A, De Maria GL, et al. Hyper-acute cardiovascular magnetic resonance $T 1$ mapping predicts infarct characteristics in patients with ST elevation myocardial infarction. J Cardiovasc Magn Reson. 2020. https://doi.org/10.1186/s12968-019-0593-9.

21. Kim HM, Kim HK, Lee JH, et al. Myocardial structural and functional changes in patients with liver cirrhosis awaiting liver transplantation: a comprehensive cardiovascular magnetic resonance and echocardiographic study. J Cardiovasc Magn Reson. 2020. https://doi.org/10.1186/ s12968-020-00622-2.

22 Le TT, Bryant JA, Ang BWY, et al. The application of exercise stress cardiovascular magnetic resonance in patients with suspected dilated cardiomyopathy. J Cardiovasc Magn Reson. 2020. https://doi.org/10. 1186/s12968-020-0598-4.

23 Qi H, Bustin A, Kuestner T, et al. Respiratory motion-compensated highresolution 3D whole-heart T1 p mapping. J Cardiovasc Magn Reson. 2020. https://doi.org/10.1186/s12968-020-00611-5.

24. Holtstiege V, Meier C, Bietenbeck M, et al. Clinical experience regarding safety and diagnostic value of cardiovascular magnetic resonance in patients with a subcutaneous implanted cardioverter/defibrillator (S-ICD) at 1.5 T. J Cardiovasc Magn Reson. 2020. https://doi.org/10.1186/ s12968-020-00626-y.

25 Podlesnikar T, Pizarro G, Fernández-Jiménez R, et al. Left ventricular functional recovery of infarcted and remote myocardium after ST-segment elevation myocardial infarction (METOCARD-CNIC randomized clinical trial substudy). J Cardiovasc Magn Reson. 2020. https://doi.org/10.1186/ s12968-020-00638-8.

26 Backhaus SJ, Lange T, Beuthner BE, et al. Real-time cardiovascular magnetic resonance $\mathrm{T} 1$ and extracellular volume fraction mapping for tissue characterisation in aortic stenosis. J Cardiovasc Magn Reson. 2020. https://doi.org/10.1186/s12968-020-00632-0.

27 Le MTP, Zarinabad N, D'Angelo T, et al. Sub-segmental quantification of single (stress)-pass perfusion CMR improves the diagnostic accuracy for detection of obstructive coronary artery disease. J Cardiovasc Magn Reson. 2020. https://doi.org/10.1186/s12968-020-0600-1.

28 Domenech-Ximenos B, Sanz-de la Garza M, Prat-González S, et al. Prevalence and pattern of cardiovascular magnetic resonance late gadolinium enhancement in highly trained endurance athletes. J Cardiovasc Magn Reson. 2020. https://doi.org/10.1186/s12968-020-00660-w.

29 Xu Y, Sun J, Wan K, et al. Multiparametric cardiovascular magnetic resonance characteristics and dynamic changes in myocardial and skeletal muscles in idiopathic inflammatory cardiomyopathy. J Cardiovasc Magn Reson. 2020. https://doi.org/10.1186/s12968-020-00616-0.

30 Kato S, Fukui K, Kodama S, et al. Incremental prognostic value of coronary flow reserve determined by phase-contrast cine cardiovascular magnetic resonance of the coronary sinus in patients with diabetes mellitus. J Cardiovasc Magn Reson. 2020. https://doi.org/10.1186/s12968-020-00667-3.

31. Liu B, Neil DAH, Premchand M, et al. Myocardial fibrosis in asymptomatic and symptomatic chronic severe primary mitral regurgitation and relationship to tissue characterisation and left ventricular function on cardiovascular magnetic resonance. J Cardiovasc Magn Reson. 2020; 22(86).

32. Kocaoglu M, Pednekar AS, Wang H, et al. Breath-hold and free-breathing quantitative assessment of biventricular volume and function using compressed SENSE: a clinical validation in children and young adults. J Cardiovasc Magn Reson. 2020; 22(54).

33. Correia T, Ginami G, Rashid I, et al. Accelerated high-resolution freebreathing 3D whole-heart $\mathrm{T}_{2}$-prepared black-blood and bright-blood cardiovascular magnetic resonance. J Cardiovasc Magn Reson. 2020; 22(88).

34. Xu L, Pagano JJ, Haykowksy MJ, et al. Layer-specific strain in patients with heart failure using cardiovascular magnetic resonance: not all layers are the same. J Cardiovasc Magn Reson. 2020; 22(81).

35. Pennig L, Lennartz S, Wagner A, et al. Clinical application of free-breathing 3D whole heart late gadolinium enhancement cardiovascular magnetic resonance with high isotropic spatial resolution using Compressed SENSE. J Cardiovasc Magn Reson. 2020; 22(89).

36. Champ-Rigot L, Gay P, Seita F, et al. Clinical outcomes after primary prevention defibrillator implantation are better predicted when the left ventricular ejection fraction is assessed by cardiovascular magnetic resonance. J Cardiovasc Magn Reson. 2020. https://doi.org/10.1186/ s12968-020-00640-0. 
37 Jacobs K, Rigdon J, Chan F, et al. Direct measurement of atrioventricular valve regurgitant jets using $4 \mathrm{D}$ flow cardiovascular magnetic resonance is accurate and reliable for children with congenital heart disease: a retrospective cohort study. J Cardiovasc Magn Reson. 2020. https://doi.org/10. 1186/s12968-020-00612-4.

38. Kranzusch R, aus dem Siepen F, Wiesemann S, et al. Z-score mapping for standardized analysis and reporting of cardiovascular magnetic resonance modified Look-Locker inversion recovery (MOLLI) T1 data: normal behavior and validation in patients with amyloidosis. J Cardiovasc Magn Reson. 2020. https://doi.org/10.1186/s12968-019-0595-7.

39. Lindemann F, Oebel S, Paetsch I, et al. Clinical utility of cardiovascular magnetic resonance imaging in patients with implantable cardioverter defibrillators presenting with electrical instability or worsening heart failure symptoms. J Cardiovasc Magn Reson. 2020. https://doi.org/10. 1186/s12968-020-00609-z.

40. Martini N, Aimo A, Barison A, et al. Deep learning to diagnose cardiac amyloidosis from cardiovascular magnetic resonance. J Cardiovasc Magn Reson. 2020. https://doi.org/10.1186/s12968-020-00690-4.

41 Olivieri LJ, Jiang J, Hamann K, et al. Normal right and left ventricular volumes prospectively obtained from cardiovascular magnetic resonance in awake, healthy, 0-12 year old children. J Cardiovasc Magn Reson. 2020. https://doi.org/10.1186/s12968-020-0602-z.

42. Qiao H, Li D, Cao J, et al. Quantitative evaluation of carotid atherosclerotic vulnerable plaques using in vivo T1 mapping cardiovascular magnetic resonance: validation by histology. J Cardiovasc Magn Reson. 2020. https://doi.org/10.1186/s12968-020-00624-0.

\section{Publisher's Note}

Springer Nature remains neutral with regard to jurisdictional claims in published maps and institutional affiliations.

- fast, convenient online submission

- thorough peer review by experienced researchers in your field

- rapid publication on acceptance

- support for research data, including large and complex data types

- gold Open Access which fosters wider collaboration and increased citations

- maximum visibility for your research: over $100 \mathrm{M}$ website views per year

At BMC, research is always in progress.

Learn more biomedcentral.com/submissions 